\title{
Integrated Safety and Process Optimization Approach for Ammonia Synthesis Loop
}

\author{
M. Athar, A. M. Shariff*, A. Buang and D. Zaini \\ Center for Advanced Process Safety (CAPS), Chemical Engineering Department, \\ Universiti Teknologi Petronas, 32610 Bandar Seri Iskandar, \\ Perak Darul Ridzuan, Malaysia \\ "Email: azmish@utp.edu.my \\ Phone: +6053687570; Fax: +6053656176
}

\begin{abstract}
Among the process safety strategies, inherent safety, proposed by Kletz, has been widely accepted and applied for the preliminary design of chemical processes. Process optimization with safety aspect has usually focused on accident costs rather than risk. Additionally, the significance of inherent assessment for process optimization has been overlooked. Simultaneous optimization of risk with inherent safety and process economics can be more impactful in practical process designs. Therefore, a new methodology is consolidated in this paper, such that an external risk and process economics model is coupled with HYSYS to achieve an optimized process design. Here, process stream index (PSI) has been suggested to identify the critical process streams. For identified critical process streams, risk analysis and process economics are studied. Risk estimation and process economics parameters are studied in an external model by extracting information from HYSYS through VBA coding. For unacceptable risk, minimization guide word is used to improve the performance of critical streams. With inherent safety implementation, process economics is also found to be improved, as $3.2 \%$ less energy would be required without any significant change in ammonia product quantity. This approach would serve to deal safety with process attributes as multiobjective optimization method of process design.
\end{abstract}

Keywords: Inherent safety; multi-objective; process streams; optimization; risk.

\section{NOMENCLATURE}

$\begin{array}{ll}\text { Alphabetical Symbols } \\ A_{h} & \text { opening area }\left(\mathrm{m}^{2}\right) \\ C_{D} & \text { discharge coefficient } \\ C_{T} & \text { fuel mole fraction concentration } \\ d & \text { diameter of the nozzle }(\mathrm{m}) \\ f & \text { fire frequency }\left(\mathrm{yr}^{-1}\right) \\ F_{P} & \text { point source view factor } \\ E_{r} & \text { radiant flux at the receiver }\left(\mathrm{kJ} / \mathrm{m}^{2} \mathrm{~s}\right) \\ m & \text { total mass }(\mathrm{kg}) \\ L & \text { length of the flame measured from the break point }(\mathrm{m}) \\ M_{a} & \text { molecular weight of the air }(\mathrm{kg} / \mathrm{kgmol}) \\ M_{f} & \text { molecular weight of the fuel }(\mathrm{kg} / \mathrm{kgmol})\end{array}$




$\begin{array}{ll}P & \text { probability } \\ p & \text { pressure }(\mathrm{kPa}) \\ x & \text { radiation path length }(\mathrm{m}) \\ \Delta H_{C} & \text { energy of combustion of the fuel }(\mathrm{kJ} / \mathrm{kg})\end{array}$

Greek Symbols

\begin{tabular}{ll}
$f$ & function of \\
$\eta$ & fraction of total energy converted to radiation \\
$\rho$ & density $\left(\mathrm{kg} / \mathrm{m}^{3}\right)$ \\
$\gamma$ & ratio of specific heat capacities, $\mathrm{C}_{\mathrm{P}} / \mathrm{C}_{\mathrm{V}}$ \\
$\tau_{a}$ & atmospheric transmissivity \\
\multicolumn{3}{|c|}{ Subscript } & Symbols \\
amb & ambient \\
del, ign & delayed ignition \\
exp/g/ign & delayed ignition leading to explosion \\
imm, ign & immediate ignition \\
$j$ & stream number
\end{tabular}

\section{INTRODUCTION}

For chemical industry safety improvement, four strategies are used: inherent, passive, active, and procedural [1-3]. Generally, inherent and passive schemes are considered as a better option. If the hazards associated with either chemicals or process are reduced or completely eliminated, it is considered as inherently safe [4]. To get the maximum benefits from this strategy, it should be implemented at the earlier design stages [5]. Whereas, inherent safety concept has been least used by industrial practitioners [6]. Inherent safety, if implemented properly, eradicates the requirement of safety systems. Further, it helps to minimize the capital and operational costs [7].

Numerous methodologies have been proposed for the evaluation of inherent safety level of the process. Most of the researchers proposed techniques using indexing methodology because of its advantages. These methods include Proto-type index for inherent safety (PIIS) [8], inherent safety index (ISI) [9], consequence-based index named as integrated inherent safety index (I2SI) $[10,11]$ and Inherent Benign-ness Indicator (IBI) [12]. These methods can identify the safer process route. A recent numerical technique has been presented to identify the safer process route to avoid the indexing method shortcomings [13]. For aforementioned techniques, manual data transfer of process parameters is needed for inherent safety level estimation. This issue has been dealt by integrated estimation tool (iRET), through integration of HYSYS, a process simulation software, and Excel spreadsheet [14]. Some other techniques using the same theme have been developed to quantify and reduce hazards [15-20].

Process design in the modern era is carried out with conflicting objectives that involve safety, economics, and environment [21]. To deal with different objectives simultaneously, a trade-off among these objectives is the best possible solution [22], and multi-objective optimization (MOO) is the best tool for this purpose [23]. To solve an MOO problem, most critical part is the correct definition of the problem [23]. For an MOO problem, there is never a single solution possible, however, a set of mathematically equally good solutions can be obtained. These solutions are known as Pareto optimal solutions [24]. 
Most of the research that has integrated safety through MOO is focusing on the cost-effective solutions. Initially, this theme has been presented through the generation of multiple accident scenarios for better investment scenario selection [25]. Pareto type curve has been used to select the optimized solution for a combination of risk and cost. This work has been extended with the development of a detailed procedure for decision making [26]. Process simulators can be used to study the modifications regarding the process or its control schemes, which can't be used for safety and environment considerations. This problem has been dealt through a systematic methodology of MOO to deal with conflicting objectives [21]. This method has been extended to safety aspects in terms of operational failure identification, which can lead to hazardous situations [22]. After identification of scenarios, modifications are proposed in the process, to improve the safety level. Finally, a study of cost estimations for proposed modifications can be helpful for optimal solution selection. A study of multi-objective optimization of safety and economics regarding the supply chain network of bio-refineries has been presented by [27]. Quantification of the risk with storage facilities along with the cost of consequences has been solved by [28]. By using quantitative risk assessment (QRA), a strategy for minimization of risk for storage facilities has been proposed [23].

This paper presents a new methodology to assimilate the inherent safety concept in terms of risk with process optimization. Recently, a framework has been presented to optimize the design based on cost and safety [4]. It includes processing cost and accident cost whereas, the effect of inherent safety scheme on equipment cost is missing. Proper selection of inherent safety guide word for optimization is missing. This paper is an attempt to integrate inherent safety along with process economic aspects.

\section{METHODOLOGY}

The framework to reduce the hazards up to acceptable range using inherent safety concept with its effect on process economics is given in Figure 1. This is a case of multi-objective optimization, and the objectives are the reduced risk and improved process economics. Both objective functions are defined in Eq. (1), while the estimation of individual objectives can be performed through Eq. (2) and (3) respectively.

$$
\text { Objective Function }=\text { Min } f(\text { Risk })_{j} \text {, Max } f \text { (Process Economics) }
$$

$$
(\mathrm{Risk})_{j}=f_{j} \times E_{r, j}
$$

Process Economics $=f($ Duty, Product Flow $)$

The constraint for this optimization problem is the early design stage, so we have less information about the process at this stage. For this study, process stream index (PSI) method has been used to identify the critical streams through relative ranking. The details and nomenclature of PSI can be found in the relevant literature [18]. Then, consequence analysis and risk estimation for identified critical streams are performed. As process streams are a replica of process piping, the fire has been selected as the outcome of pipe leakage based on accidents data knowledge. 


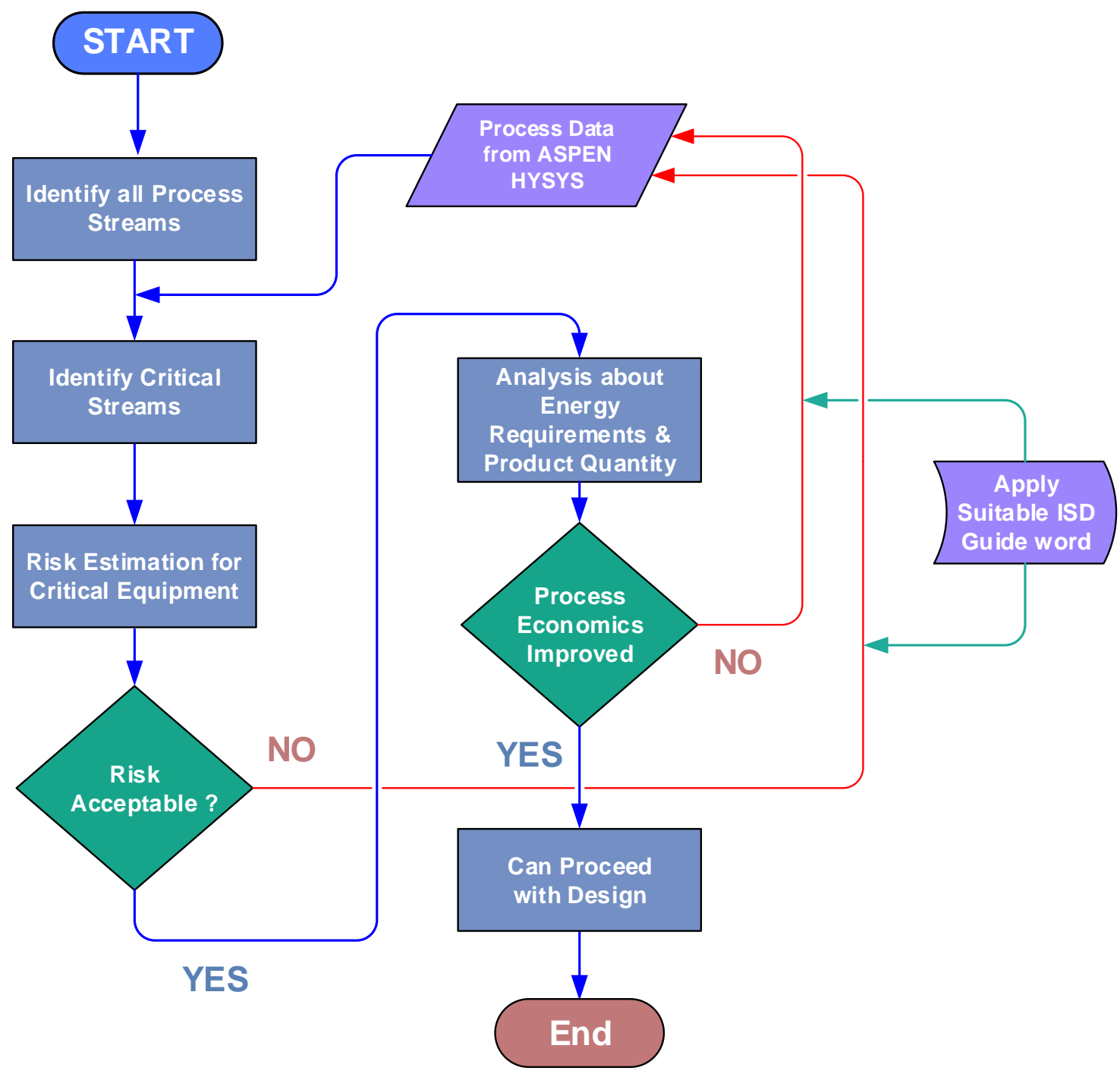

Figure 1. Framework for integrated safety and optimization scheme.

The necessary equations of fire consequence estimation are given by Eq. (4) to (7) [29]. While the fire frequency can be estimated from Eq. (8) [30].

Estimation of flammable mass

$$
m=C_{D} A_{h} \sqrt{\gamma p \rho\left(\frac{2}{\gamma+1}\right)^{\gamma+1}}
$$

$$
\frac{L}{d}=\frac{15}{C_{T}} \sqrt{\frac{M_{a}}{M_{f}}}
$$

Point view source factor

$$
F_{P}=\frac{1}{4 \pi x^{2}}
$$

Radiation intensity at point of interest $E_{r}=\tau_{a} \eta m \Delta H_{C} F_{P}$ 


$$
f=\left[f_{I L} \times P_{\text {imm,ign }}\right]+\left[f_{I L} \times\left(1-P_{\text {imm,ign }}\right) \times\left(P_{\text {del, ign }}\right) \times\left(1-P_{\text {exp } / g / i g n}\right)\right]
$$

Fire consequences and frequencies are available in literature and the whole range of risk is spread from 1 to 36 based on the magnitude. It has been divided into three groups, i.e., 1 to 8 is acceptable, 9 to 24 is tolerable and 25 to 36 is unacceptable. The risk after implementation of all cost-effective measures to reduce the risk is termed as a tolerable risk. If the risk is not acceptable, the modification is carried out using ISD guide word. For this study, moderation guide word is proposed, and it is used with process conditions. Next is the process economic analysis, for which energy requirements and product quantity are obtained from HYSYS. Both risk and process economics parameters can be plotted against the modifications and this can help to identify the optimum conditions for the process. If the risk is not acceptable, aforementioned inherent safety guide word is used and loop runs again and again until the risk is acceptable. Next, process economic analysis is performed by checking duty requirements and product flow rate from HYSYS. If the duty requirements are less and product flow rate is increased, the process economics is improved, and the designer can proceed with the design. Otherwise, the modification is needed in a choice of inherent safety guide word or magnitude of already selected guide word. At the end of this loop, the designer is available with a process that is optimized in terms of inherent safety as well as in economic aspects.

\section{RESULTS AND DISCUSSION}

Ammonia synthesis process plant has been selected to study the integrated safety and optimization methodology described above. Industrially, ammonia is produced by the reaction of nitrogen and hydrogen in the gaseous phase. Conversion from the reactor is very less, so recycling of reactants is feasible to recover the unconverted reactants. To store the product, the gaseous ammonia is cooled down in a heat exchanger network and then liquid ammonia is separated from the gas mixture in a separator. Ammonia synthesis loop has total 40 number of streams, and the process simulation of the process is given in Figure 2[31].

PSI concept has been applied to all process streams to identify the critical process streams [18]. The PSI values of all process streams are given in Table 1. Based on the magnitude of PSI values, process stream Product Ammonia is identified as the most critical, while streams 2a, 2, 60, 17, 21, 22 and 23 are the next in the list respectively. Product Ammonia is more prone to leak because of all parameters considered in PSI technique. Although individual parameters for other process streams are high, however, for overall aspect, Product Ammonia emerges as the most prominent. Risk estimation for the pipe rupture is used to estimate consequences of fire outcome for aforementioned streams. Risk consequences are noted for a distance of $4 \mathrm{~m}$ from the source of leakage. The risk for Product Ammonia stream is acceptable, while for rest of the streams, it is tolerable. The product flow rate and energy requirements are also obtained for the process from HYSYS. 


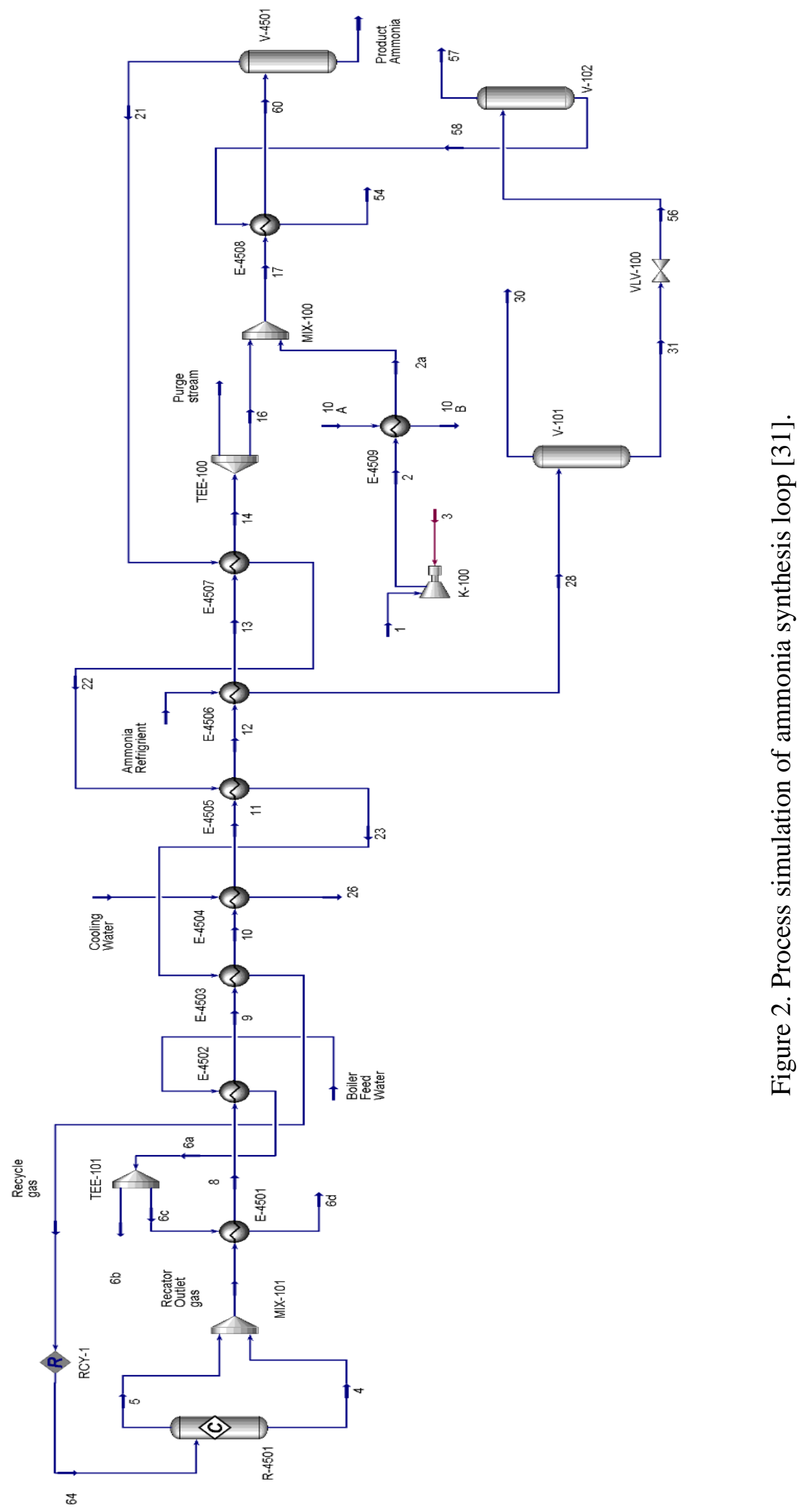


Table 1. The relative ranking of process streams.

\begin{tabular}{lccccc}
\hline Stream Name & $\mathrm{I}_{\mathrm{e}}$ & $\mathrm{I}_{\mathrm{P}}$ & $\mathrm{I}_{\rho}$ & $\mathrm{I}_{\mathrm{FL}}$ & PSI \\
\hline 1 & 1.83 & 0.83 & 0.10 & 3.70 & 5.32 \\
2 & 1.83 & 1.44 & 0.13 & 3.70 & 12.85 \\
4 & 0.99 & 1.44 & 0.16 & 0.00 & 0.00 \\
5 & 1.00 & 1.44 & 0.16 & 1.02 & 2.31 \\
Reactor Outlet gas & 1.00 & 1.44 & 0.16 & 1.02 & 2.31 \\
8 & 1.00 & 1.44 & 0.19 & 1.02 & 2.83 \\
9 & 1.00 & 1.44 & 0.21 & 1.02 & 3.05 \\
10 & 1.00 & 1.44 & 0.39 & 1.02 & 5.68 \\
11 & 1.00 & 1.44 & 0.45 & 1.02 & 6.65 \\
12 & 1.00 & 1.44 & 0.47 & 1.02 & 6.91 \\
13 & 1.00 & 1.44 & 0.51 & 1.02 & 7.48 \\
14 & 1.00 & 1.44 & 0.53 & 1.02 & 7.76 \\
Purge stream & 1.00 & 1.44 & 0.53 & 1.02 & 7.76 \\
16 & 1.00 & 1.44 & 0.53 & 1.02 & 7.76 \\
17 & 1.11 & 1.44 & 0.42 & 1.49 & 9.91 \\
Product Ammonia & 1.71 & 1.44 & 2.16 & 0.75 & 39.95 \\
21 & 1.03 & 1.44 & 0.40 & 1.62 & 9.63 \\
22 & 1.03 & 1.44 & 0.38 & 1.62 & 9.04 \\
23 & 1.03 & 1.44 & 0.35 & 1.62 & 8.40 \\
Recycle gas & 1.03 & 1.44 & 0.19 & 1.62 & 4.58 \\
Boiler Feed Water & 0.00 & 1.39 & 2.69 & 0.00 & 0.00 \\
6a & 0.00 & 1.39 & 2.53 & 0.00 & 0.00 \\
$6 \mathrm{~b}$ & 0.00 & 1.39 & 2.53 & 0.00 & 0.00 \\
$6 \mathrm{c}$ & 0.00 & 1.39 & 2.53 & 0.00 & 0.00 \\
6d & 0.00 & 1.39 & 0.22 & 0.00 & 0.00 \\
Cooling Water & 0.00 & 0.03 & 3.43 & 0.00 & 0.00 \\
26 & 0.00 & 0.03 & 3.41 & 0.00 & 0.00 \\
Ammonia Refrigerant & 1.68 & 0.06 & 2.12 & 0.74 & 1.62 \\
28 & 1.68 & 0.06 & 0.04 & 0.74 & 0.03 \\
30 & 1.68 & 0.06 & 0.02 & 0.74 & 0.01 \\
31 & 1.68 & 0.06 & 2.12 & 0.74 & 1.62 \\
54 & 1.68 & 0.02 & 0.01 & 0.74 & 0.00 \\
56 & 1.68 & 0.02 & 0.08 & 0.74 & 0.02 \\
57 & 1.68 & 0.02 & 0.01 & 0.74 & 0.00 \\
58 & 1.68 & 0.02 & 2.22 & 0.74 & 0.69 \\
$2 \mathrm{a}$ & 1.83 & 1.44 & 0.16 & 3.70 & 16.02 \\
64 & 1.03 & 1.44 & 0.19 & 1.62 & 4.58 \\
10 A & 0.00 & 0.03 & 3.43 & 0.00 & 0.00 \\
10 B & 0.00 & 0.03 & 3.40 & 0.00 & 0.00 \\
\hline & & & & & \\
\hline
\end{tabular}

Although these critical streams except Product Ammonia are well below unacceptable values, inherent safety guide word moderation is applied, such that the risk can be minimized to acceptable values. Moderation guide word is combined with process conditions. Iteration method has been used for moderation of process conditions. After each iteration, risk estimation is performed to see the effect on risk of these streams. The 
analysis is carried out for the amount of product and required energy, to see the effect of moderation guide word on process economics. For identified critical streams, values for risk, energy requirements and ammonia product flow rate for initial conditions and all iterations using moderation guide word are shown in Figure 3(a) to (f). Analyzing the results of our objectives of minimum risk and better process economics, new process conditions have been chosen, given in Table 2. To represent the different categories of risk, the graph is divided into the regions. Above the red line, the risk is unacceptable and below green line, it is acceptable. While area between red and green lines is the tolerable region.

Table 2. Initial and final process conditions for critical streams.

\begin{tabular}{ccccc}
\hline Stream name & $\begin{array}{c}\text { Original } \\
\text { pressure } \\
(\mathrm{kPa})\end{array}$ & $\begin{array}{c}\text { Modified } \\
\text { pressure } \\
(\mathrm{kPa})\end{array}$ & $\begin{array}{c}\text { Original } \\
\text { temperature } \\
\left({ }^{\circ} \mathrm{C}\right)\end{array}$ & $\begin{array}{c}\text { Modified } \\
\text { temperature } \\
\left({ }^{\circ} \mathrm{C}\right)\end{array}$ \\
\hline Product Ammonia & $14,219.6$ & 11,376 & -4.0 & -3.4 \\
$2 \mathrm{a}$ & $14,219.6$ & 11,376 & 40.0 & 38.0 \\
2 & $14,219.6$ & 11,376 & 117.0 & 83.0 \\
60 & $14,219.6$ & 11,376 & -4.0 & -3.4 \\
17 & $14,219.6$ & 11,376 & 9.1 & 8.4 \\
21 & $14,219.6$ & 11,376 & -4.0 & -3.4 \\
22 & $14,219.6$ & 11,376 & 9.8 & 11.4 \\
23 & $14,219.6$ & 11,376 & 30.2 & 31.5 \\
\hline
\end{tabular}

After the iterations, the risk for critical streams is still in the tolerable region, however, the magnitude and effects are reduced. The mass released and the radiation intensity of for these streams is reduced up to $25 \%$. The frequency of the ignition of mixtures in process pipes is already very less. So, to obtain the acceptable risk, radiation intensity needs to be reduced up to $61 \%$, while the process conditions for such reduced level of fire intensity are not practically possible based on the reaction kinetics.

The fire radiation intensity and process energy requirements have been decreased gradually by lowering process conditions, while the product molar flow has initially decreased and then increased. The product flow rate, after moderation in process conditions, is less than the original process conditions. Initially, the process conditions are thermodynamically more stable to achieve more ammonia in the liquid phase. For the first iteration, it has decreased suddenly because of unstable thermodynamic compatibility. On further iterations, the thermodynamic conditions have become better and better, and ammonia molar flow rate in the liquid phase is increased. This slight compromise in the product flow rate has caused great impacts on energy and safety. Although the reduction in process conditions puts a heavy load on certain heat exchangers, most of the heat exchangers have shown significant load reduction. For the duty of the whole process, it has decreased significantly.

All parts i.e., compressor and exchanger observe a smooth declining trend. The final conditions in Table 2 are the optimized conditions for this process. These conditions can be compared with initial to show the significance of reduced energy requirements because of reduced compressor load and cooling water requirements. 

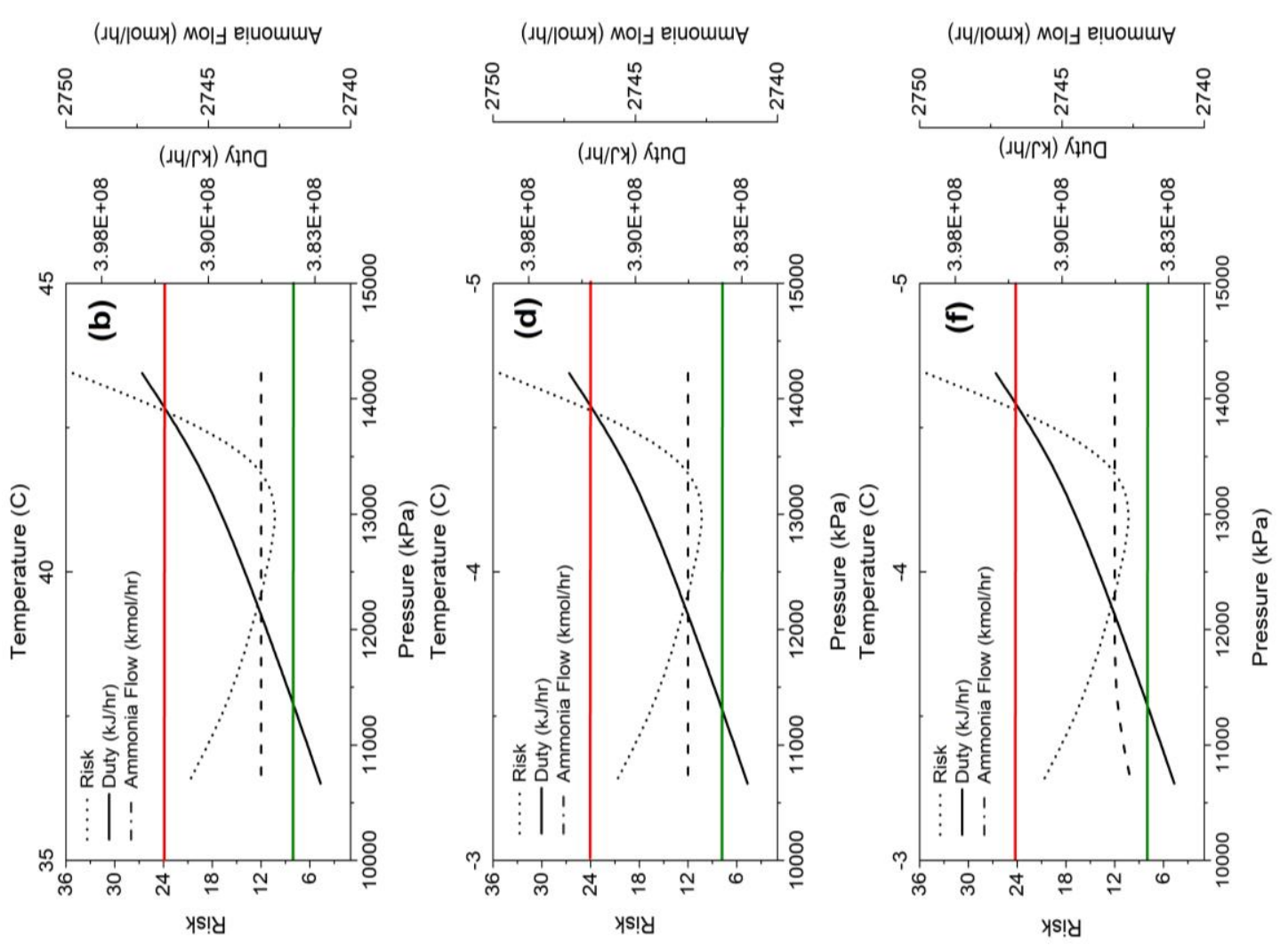

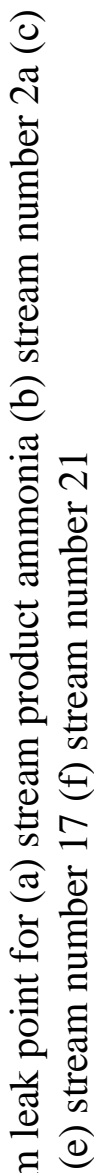
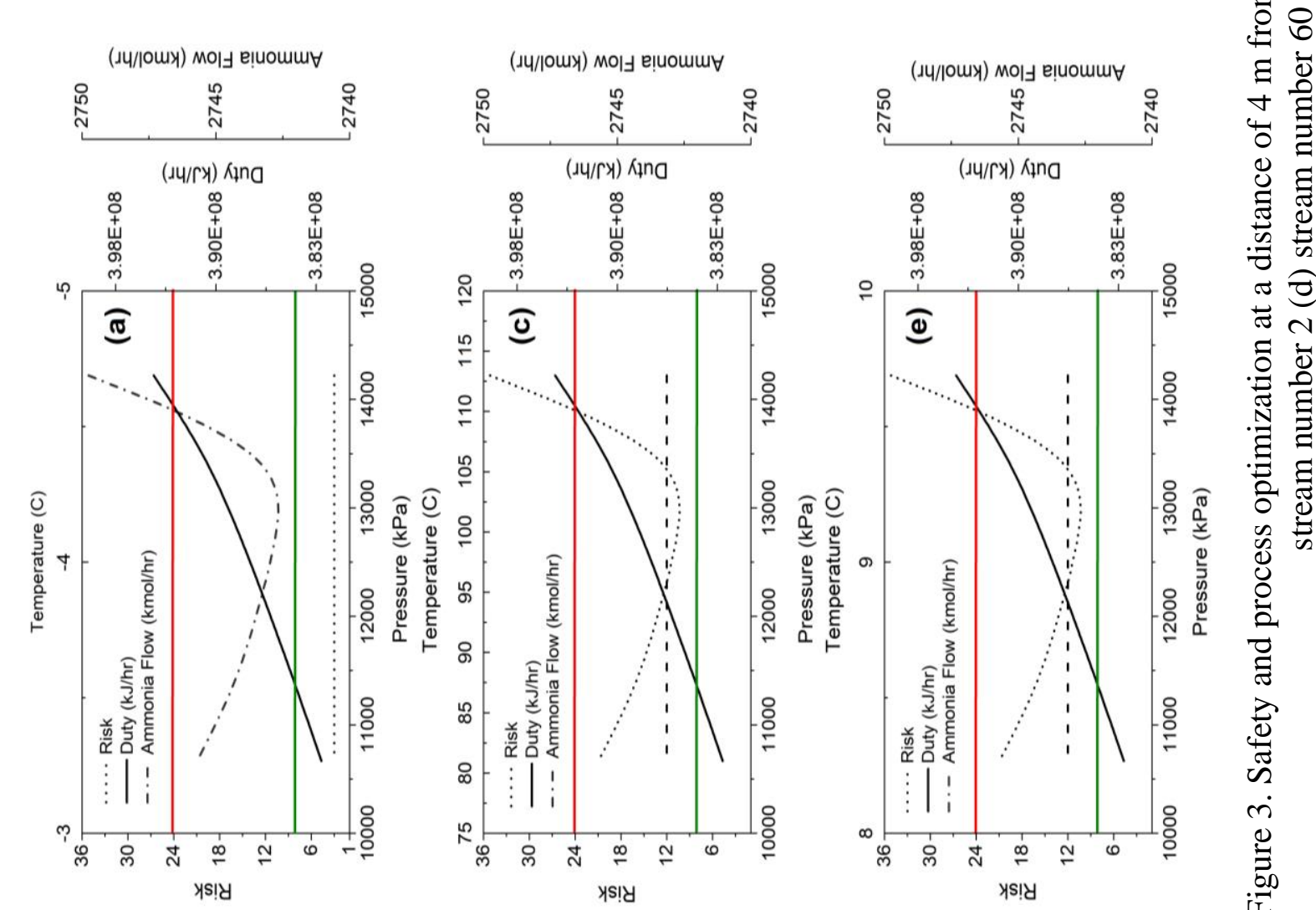

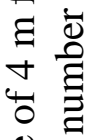

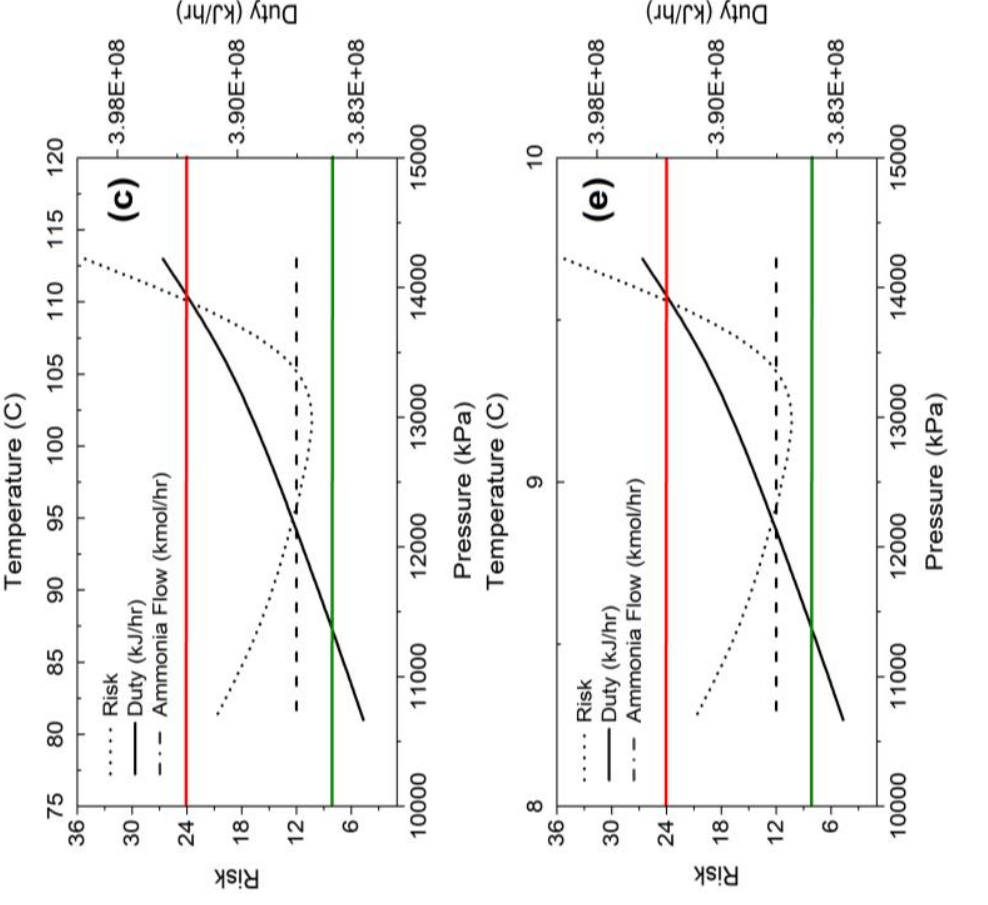

苟 
Overall, the risk is minimized in terms of radiation intensity for all critical streams, and process economics is improved because of $2.7 \%$ fewer duty requirements and increased product flow rate, depicted in Figure 3(a) to (f). For future work, more case studies can be performed for improvement of suggested methodology. Further, as the operating conditions are changed, the rating of the process vessels and piping is changed. This will reduce the material cost during fabrication i.e. installed cost is reduced. However, this is not the scope of this study, as it is beyond the aspects of the basic design stage.

\section{CONCLUSION}

Inherent safety is the best possible strategy for improving safety level of a process plant. However, the modern design requirements have multiple conflicting objectives like safety, economics, and environment. Accident cost has been previously used to measure the safety, which does not indicate about hazard acceptability. Proper use of inherent safety guide word is missing, to integrate with process economics. A framework has been proposed in this work, which identifies critical process stream, implement proper inherent safety guide word, and analyzes its effect on safety and process economics to make a decision. Study of ammonia synthesis process was conducted using the proposed framework. Process streams were studied using PSI technique, and moderation of process conditions was selected as guide word. Lowering the process condition resulted in improving the safety level as the risk was in acceptable range. On the other hand side, process economics was improved in terms of minimized duty requirements for the process and increasing amount of product from the same amount of feed stock.

\section{ACKNOWLEDGEMENT}

The authors are obliged to Universiti Teknologi PETRONAS, Malaysia for providing facilities and funding to make this research feasible.

\section{REFERENCES}

[1] Hendershot DC. An overview of inherently safer design. Process safety progress. 2006;25:98-107.

[2] Hendershot DC. A summary of inherently safer technology. Process Safety Progress. 2010;29:389-92.

[3] Hendershot DC. Inherently safer design: an overview of key elements. Professional Safety. 2011;56:48.

[4] Eini S, Abdolhamidzadeh B, Reniers G, Rashtchian D. Optimization procedure to select an inherently safer design scheme. Process Safety and Environmental Protection. 2015;93:89-98.

[5] CCPS, Center for Chemical Process Safety. Inherently Safer Chemical Processes: A Life Cycle Approach. 2 ed: John Wiley \& Sons; 2010.

[6] Moore DA, Hazzan M, Rose M, Heller D, Hendershot DC, Dowell AM. Advances in inherent safety guidance. Process Safety Progress. 2008;27:115-20.

[7] Hendershot DC. Process minimization: making plants safer. Chemical engineering progress2000. p. 35-40.

[8] Lawrence D. Quantifying inherent safety of chemical process routes $[\mathrm{PhD}$ Thesis]: Loughborough University of Technology; 1996. 
[9] Heikkilä A-M. Inherent safety in process plant design: an index-based approach [PhD Thesis]: VTT Technical Research Centre of Finland; 1999.

[10] Khan FI, Amyotte PR. Integrated inherent safety index (I2SI): a tool for inherent safety evaluation. Process safety progress. 2004;23:136-48.

[11] Khan FI, Amyotte PR. I2SI: a comprehensive quantitative tool for inherent safety and cost evaluation. Journal of Loss Prevention in the Process Industries. 2005;18:310-26.

[12] Srinivasan R, Nhan NT. A statistical approach for evaluating inherent benign-ness of chemical process routes in early design stages. Process Safety and Environmental Protection. 2008;86:163-74.

[13] Ahmad SI, Hashim H, Hassim MH. Numerical descriptive inherent safety technique (NuDIST) for inherent safety assessment in petrochemical industry. Process Safety and Environmental Protection. 2014;92:379-89.

[14] Shariff AM, Rusli R, Leong CT, Radhakrishnan V, Buang A. Inherent safety tool for explosion consequences study. Journal of Loss Prevention in the Process Industries. 2006;19:409-18.

[15] Leong CT, Shariff AM. Inherent safety index module (ISIM) to assess inherent safety level during preliminary design stage. process safety and environmental protection. 2008;86:113-9.

[16] Leong CT, Shariff AM. Process route index (PRI) to assess level of explosiveness for inherent safety quantification. Journal of Loss Prevention in the Process Industries. 2009;22:216-21.

[17] Shariff AM, Leong CT. Inherent risk assessment - a new concept to evaluate risk in preliminary design stage. Process Safety and Environmental Protection. 2009;87:371-6.

[18] Shariff AM, Leong CT, Zaini D. Using process stream index (PSI) to assess inherent safety level during preliminary design stage. Safety science. 2012;50:1098-103.

[19] Shariff AM, Zaini D. Toxic release consequence analysis tool (TORCAT) for inherently safer design plant. Journal of hazardous materials. 2010;182:394-402.

[20] Shariff AM, Zaini D. Inherent risk assessment methodology in preliminary design stage: a case study for toxic release. Journal of Loss Prevention in the Process Industries. 2013;26:605-13.

[21] Ramzan N, Witt W. Methodology for decision support among conflicting objectives using process simulators. Computer Aided Chemical Engineering. 2006;21:415-20.

[22] Ramzan N, Naveed S, Feroze N, Witt W. Multicriteria decision analysis for safety and economic achievement using PROMETHEE: A case study. Process Safety Progress. 2009;28:68-83.

[23] Bernechea EJ, Arnaldos J. Optimizing the design of storage facilities through the application of ISD and QRA. Process Safety and Environmental Protection. 2014;92:598-615.

[24] Branke J, Deb K, Miettinen K, Slowinski R. Multiobjective Optimization: Interactive and Evolutionary Approaches: Springer; 2008.

[25] Kim D, Ko D, Kim J, Park M, Moon I. Automatic accident scenario generation and multiobjective optimization for safety-related decision making in chemical processes. European Symposium on Computer Aided Process Engineering-14 meeting, Lisbon, Portugal2004. 
[26] Kim D, Kim J, Moon I. Integration of accident scenario generation and multiobjective optimization for safety-cost decision making in chemical processes. Journal of loss prevention in the process industries. 2006;19:705-13.

[27] El-Halwagi AM, Rosas C, Ponce-Ortega JM, Jiménez-Gutiérrez A, Mannan MS, El-Halwagi MM. Multiobjective optimization of biorefineries with economic and safety objectives. AIChE Journal. 2013;59:2427-34.

[28] Bernechea EJ, Viger JA. Design optimization of hazardous substance storage facilities to minimize project risk. Safety science. 2013;51:49-62.

[29] CCPS, Center for Chemical Process Safety. Guidelines for chemical process quantitative risk analysis: Center for Chemical Process Safety/AIChE; 2000.

[30] Moosemiller M. Development of algorithms for predicting ignition probabilities and explosion frequencies. Journal of Loss Prevention in the Process Industries. 2011;24:259-65.

[31] Pasha M, Zaini D, Mohd Shariff A. Inherently safer design for heat exchanger network. Journal of Loss Prevention in the Process Industries. 2017;48:55-70. 